\title{
Gendered Experiences of Female Engineering Students in Selected Public Universities in Zambia
}

\author{
Heather Munachonga*, Ecloss Munsaka \\ University of Zambia, School of Education, Lusaka. Zambia \\ *Corresponding Author: Heather Munachonga, University of Zambia, School of Education, Lusaka. \\ Zambia
}

\begin{abstract}
This article is an extract from an ongoing PhD study which was guided by a question that sought to examine the lived experiences of female engineering students at two public universities in Zambia. An Interpretative Phenomenological Analysis (IPA) was used. The sample which was purposely selected comprised 14 fifth year female engineering students, 7 from each university. Semi structured interviews were used because these are commonly used with IPA. Transcription of each individual interview was done after each interview session and later common themes were clustered. The study found that the female students encountered academic and social experiences which took a gender outlook and others which were not gender specific both in their social and academic environments. The study showed that the academic environment was largely male dominated in terms of lecturers and students; there was positive discrimination in both institutions favouring the female students to major in engineering despite not attaining the required cut off point in the qualifying examination; and there was subtle sarcasm against females, there was negative discrimination and some experiences of vulnerability. In conclusion the paper argues that a female friendly environment would encourage participation and retention of female engineering students.
\end{abstract}

Keywords: Engineering, female students, gendered experiences, public universities, Zambia

\section{INTRODUCTION}

The experiences of the female students who pursue engineering at university in Zambia are not known, which is a source of concern as engineering education is male dominated at this level. While it is known that admission to university in Zambia's public universities is based on marks scored in High School and the cut-off points, it is also possible that there are other factors influencing the choice of engineering and the ability to remain persistent while studying in the male dominated faculties. This study was undertaken to understand the experiences of female engineering students at university level, their choice to study engineering and subsequently the persistence to complete the programme as well as the possible support which could be given to female engineering students.

The underrepresentation of females in the field of engineering is not unique to Zambia. Starobin and Lanaan (2005) point out that this is both a historical and global phenomenon. Suffice to say that recent global trends reveal an increase in women enrolling in engineering especially in countries such as the United Kingdom and France (Mahani \& Molki, 2011). This may be the case with Zambia but probably the increase may not be significant.

Known research studies in Zambia continue to ignore this unfortunate scenario in spite of the growing discourse about the importance of firstly, local engineers as a critical resource, and secondly, educating and promoting women in science, for the sustainable socioeconomic development. The common stereotype has been that it is difficult for females to obtain a University engineering degree in Zambia (Chongo, 2015). Such a postulation lacks empirical evidence as no known studies have been conducted in Zambia to establish the extent to which this stereotype is valid.

The study was situated in Bronfenbrenner's Ecological Systems theoretical framework which provided the basis on, and perspective from, which to understand how ecological systems in the environment where the individual lives, influence the individual. The human ecology theory emanates from assumptions that individuals and environments are intertwined and depicts the interactions and transactions of people in a range of contexts. Therefore, with reference to this study, situating it in the 
ecological model suggests that one way that the drive to pursue a particular course may be shaped through interactions with immediate environment and other relationships within the environment. Subsequently the environment may influence the female engineering students' capability to be resilient in their studies.

\section{STATEMENT OF THE PROBLEM}

Despite engineering programmes being incentivized to attract and sustain female students at university level in Zambia, few females opt to study engineering. While this is the case, there is no known study that has been conducted to understand the experiences of female engineering students at university in Zambia. The lack of information on such experiences of female engineering students deprives relevant institutions of practical insights into what could possibly be done to provide support to female engineering students in order for them to succeed and attract more female students in the programmes. To widen participation, it is important to understand at what point female students decide to study engineering at University, which factors influence their decision, and how they remain persistent in the school of engineering.

\subsection{Objective}

To examine experiences of female engineering students in the School of Engineering

\subsection{Research Question}

What are the experiences of female engineering students in the School of Engineering?

\section{LiTERATURE REVIEW}

Studies undertaken elsewhere on female engineering students were reviewed and this literature was used to interpret and understand the findings in addition to the theory. A study was conducted in Japan by Hosaka (2013) to investigate experiences that Japanese women have as engineering undergraduates while interacting with departmental faculty. She collected data using interviews from 32 final-year students at two universities in Japan. The theory of 'role as resource' was used as the theoretical framework. Findings suggested that the women's feelings of alienation in engineering classes were due to instructors' poor teaching and aloofness, which influenced both their lack of engagement in learning (in and outside the classroom) and the difficulties they perceived in approaching instructors with academic questions. The female students used various strategies when they decided to approach departmental faculty, based on their level of understanding of the subject matter and the extent to which they felt comfortable initiating contact. Availability of peer assistance also determined whether students asked questions of instructors. Despite satisfactory encounters, participants typically did not develop ease with the departmental faculty.

Women in science and engineering have a long history of feeling marginalized, isolated, and subject to stereotype threats within their majors, a feeling that tends to grow over time (Maehr et al. 2009). Reports of bias in the form of sexual harassment from classmates and faculty are all too common for undergraduate women in science and engineering (Morris \& Daniel 2008). An early study on chilly climate found that women in male-dominated fields perceived their ideas as less valuable and unwelcomed in comparison to those of male peers (Hall and Sandler 1982).

Madara and Cherotich (2016) cite a number of studies with challenges on female engineering students and assert that female students face extra challenges in learning engineering courses. The challenges varied and cannot be exhaustively mentioned in one study. Therefore, the following synopsis on challenges does not capture all challenges: Self Perception of Ability (Girls consider themselves lower than boys with same mathematical ability) (Correll, 2001); in Math and Science Abilities (Loss of self-confidence in these subjects was found to be correlated with dropouts and uncorrelated with performance) (Brainard, 1998); Isolation (Reports of female isolation increased substantially during the 4-year degree program (Brainard, 1998); Intellectual Intimidation: Behavior of Males in Group Environments (perpetuated by stereotypes. Women report male comments of inappropriate jokes, make them feel unwelcome, devalue them) (Seymour 1995); Overall Confidence (Lack of selfconfidence increases throughout university years). These trends are associated with other environmental factors related to institutional setting (Brainard 1998; Hill, 2010).

Numerous studies in the U.S. cite trends of females in engineering programs reporting feelings of isolation or psychological alienation due to a male-dominant environment where male students were 
often hostile toward female students (GAO, 2004). According to Schaefer (2006) some of the challenges established facing female students in learning the engineering courses were ridiculing, intimidation, labeling, teasing and belittling. These challenges could impact negatively on participation, performance, and gender disparities in productivity and employment opportunities.

\section{Methodology}

The study took a qualitative approach because it aimed at understanding lived experiences of female engineering students. Interpretative Phenomenological Approach was chosen because of its flexibility and being inductive blended well with the questions the study sought to answer; and it further allowed for different levels of interpretation (Brocki and Wearden, 2006). Thus, this method allowed the researcher to interpret the interpretations of the respondents of how they made sense out of their experiences.

The study was conducted at University of Zambia and Copperbelt University because at the onset of the study, those were the only universities offering full time degree engineering courses in the country. The sources of data were female engineering students at both universities. The sample of this study consisted of 14 female students, 7 of who were from University of Zambia and 7 from Copperbelt University. This small sample size was preferred in this study to allow the researcher to delve into the lived experiences of the female students. The elements of the sample were selected from electrical engineering, mechanical engineering, telecommunications engineering and civil engineering female students. Individual interviews were used and later each interview was transcribed.

In line with the theoretical underpinnings of IPA, participants were selected purposively. This allowed the researcher to find a defined group for whom the research problem had relevance and personal significance. Purposive sampling was chosen because the focus was on respondents who had attributes of what the research was on. This group was homogeneous in the sense that they shared the experiences of a particular condition, event or situation which they were asked to describe to the researcher (Willig, 2001). Sampling targeted fifth year female engineering students with an understanding that they had reached the end of their academic journey making it easy for them to look back and relive the entire episode of their academic journey at university and give rich descriptions of their experiences.

Using a semi structured interview guide, the researcher conducted interviews to collect data from 14 final year female engineering students. Permission to undertake the study was obtained from the University of Zambia Ethics Committee to conduct the study and when clearance was granted, the researcher sought permission from the Ministry of Higher Education under which the Universities belonged. Later permission was sought from University authorities at both universities and participants themselves. Confidentiality was upheld and participants voluntarily participated in the research knowing they could back out any time they deemed fit.

\section{FINDINGS AND DISCUSSION}

Participants shared varied experiences but this article focuses on academic and social experiences that were gender specific. Gender specific experiences manifested in form of Positive discrimination or Affirmative Action (AA) which favoured female students to qualify to School of Engineering and further into their major disciplines, male dominated classroom environments, subtle treatment of being a weaker gender, negative sarcasm against females and females opting to act like males.

Both Universities practiced positive discrimination which presented itself in form of Affirmative Action that existed at two levels. Firstly, it existed at the end of first year when female students sat for end of year examination in order to migrate from the School of Natural Science to School of Engineering. The AA entailed lowering of the cut-off point for female students in order to qualify to the School of Engineering. This was consistent with Madara's (2016) finding of a similar practice at University in Kenya where there was a Lower admission cut- off points for females, a policy which allowed female candidates who had attained the minimum required marks to enter public universities at one (1) point below males. Secondly, there was an examination at the end of first year in the School of Engineering to qualify to major in sub disciplines of their choice. Again at this level the cut-off point was relaxed in favour of female engineering students as long as they had passed the examination they were allowed to pursue a sub discipline of their choice. A participant from Copperbelt University rrmarked, 'There is never any female who has been denied an opportunity to do engineering,' [Kon] 
and another from University of Zambia confirmed that, 'In second year we were supposed to make points to be put in quotas but for the females even if you haven't really done well, but cleared all exams you do whatever engineering programme you want.' [Ene].

Apart from affirmative action as an enabler to majoring in engineering, the study highlights that some female engineering students opted to major in engineering in order to challenge the existing status quo. Remarks of engineering being a male programme and that females failed engineering were common in university before entering the engineering school. This motivated some females to study engineering to prove to the world that even females could successfully study hard courses such as engineering. A female student who repeatedly heard a lecturer boast about being the only engineer in his sub discipline had this to say, 'I chose Mechatronics because I wanted to prove to the males like him that others even females can do it.' [Len].

While some participants reported equal treatment with the male students in class, others reported subtle experiences of differential treatment in their courses where some lecturers sometimes passed verbal or silent messages emphasizing femininity which reminded them that they were female in a male dominated environment. Most lecturers reportedly paid more attention to female engineering students than male students in the lecture room while teaching because they wanted to encourage them to participate in school work so that they could not be left behind but understood concepts like their male counterparts. However, some female engineering students took it that lecturers thought females needed help and extra effort to make it in engineering. Similarly, McLoughlin (2005) identified 'spotlighting' which is the singling out of women, whether overtly, tacitly, or with the intention to help them, as a direct or indirect cause of gender-bias difficulties. However, a participant had this to say, 'I must say there are times when I felt like, I have been treated like a weaker part of the class.'[Nad] Therefore helpful as singling of women may be viewed, the gesture indirectly implied that female engineering students needed extra help for them to understand thereby augmenting the masculinity associated with engineering that it was meant for males.

The male dominated environment presented a climate which prevented some female engineering students from asking questions even where they did not understand concepts because they did not want to be viewed as time wasters by the male students in the classroom. Similarly Fleming, Kimarie and Griffin (2005) reported that engineering classroom environment was full of challenges, such as: female students being very few and afraid to ask questions for fear of being ridiculed. The participants reported being looked down upon by male students as exemplified in this excerpt, "It is hard to have study partners who are guys because you are always looked down upon. In my class, there is that element that you feel that males feel like you can't tell them anything because you are a girl, they view you differently,' [Tao].Therefore, male dominance posed challenges to female students in learning engineering courses because males consciously or unconsciously sent messages to female students that they were unwelcome in class discussions (Kelly, 2000). Consequently this male dominance influenced some female engineering students to start behaving like male students in order to fit in as recounted by a participant, 'Most girls who are doing engineering want to act like guys, sometimes going about with unkempt hair and dry lips.' [Tao].

More importantly, the female engineering students were sometimes intimidated due to the absence of female lecturers in the engineering lessons. 'The lack of female lecturers like when we are presenting for example is intimidating to be only surrounded by men asking you questions.' [Lala]. Discussing the challenges faced by female engineering students in Kenya, StarovoytovaMadara and Cherotich (2016) point out that the unique benefit of same-sex role models simultaneously allows females to develop a successful sense of self in STEM while embracing their gender identity. For Blickenstaff (2005), a low proportion of women in a discipline sends a message to females that the discipline is unattractive to women, and they should avoid it too. Therefore absence of female engineering students was another silent message to the female engineering students that engineering was a programme for males. The absence also deprived the female engineering students of confidants to share their personal problems with with a view to getting help as recounted, you can't go to your lecturer and say I have cramps so I miss class because most of our lecturers are male who cannot address our personal issues as females.' [Lin]

Mathematics was referred to as a 'killer mathematics because it threatened to kill the dream of becoming female engineers. A participant from Copperbelt university had this to say, 'Math is viewed 
to be a killer especially for girls,' [Ren]. Seeing mathematics from the same perspective, female a participant from University of Zambia said, 'Third year Mathematics is the 'killer Mathematics' in the school of engineering which can kill one's dreams and it is the most failed so many struggle with it.' [Wendi]. Therefore female engineering students' experience in mathematics was that it was a hard curse which the majority of females that failed usually failed mathematics.

There were messages of subtle sarcasm against female engineering students as some male lecturers and male students sometimes made comments about female engineering students in their presence which the females considered offensive but the males would pretend to be joking. These findings were not unique to this particular study because Hall and Sandler (1982) cited overt examples of the chilly climate experienced by females in a male dominated academic environment which included 'making disparaging comments about women; disparaging women's intellectual abilities; implying that women lack commitment; making comments about women's physical attributes or appearance; and making direct sexual overtures to women" (p.4).

Some female engineering students feared to interact with males. Firstly, there were female students who initially feared to interact with male students because they came from girls only High Schools so were not used to interacting with males. However, over time they began to interact with them because of their interest to learn and they saw males as strong students in the hard sciences. This was akin to Chou and Chen (2015) who reported similar findings that females who graduated from single gender High Schools were uncomfortable with male-dominated learning environments after entering engineering schools. Secondly, there were female students who interacted with males students but rather feared to go to male lecturers' offices because other students would suspect them that they were dating lecturers in order to solicit for good marks in assignments and assessments.

Related to this were experiences of vulnerability because some males seemingly wanted to take advantage of females. A participant from the University of Zambia remarked, 'What I don't like about guys in the school of engineering is that the majority just want to date or have sex with you,' [Tao].Similarly another participant from the other institution noted, 'Being in a relationship can be good but guys can take advantage of you because they think she loves me so she will cook and wash for me so your mind stops focusing on books to focusing on being a wife.' [Kon]. Therefore males in one way or another took advantage of the female students by seeing them as sexual objects that could be used for masculine selfish motives.

More importantly, these female students faced social isolation because fellow female students as well as male students who were not in engineering school did not want to mingle with them. This isolation experienced entailed that male students from other faculties could not date them because being an engineering student was synonymous with unmatched intelligence which was intimidating to nonengineering students. A participant had this to say, 'It's really hard to connect and make friends from other schools,' [Tao]. Their peer network therefore was limited. Another participant said, guys can't approach a woman who does engineering because then she is too serious [Zen]. Related to social isolation, in one institution the female engineering students experienced negative discrimination of not having a female-specific toilet in the main School of Engineering building but used a toilet that was meant for the staff. A participant said, 'I learnt from a lecturer that school of engineering was built for males so you find on the ground floor a toilet for ladies is labelled 'staff only', maybe it was meant for a secretary.[Mel].This posed a challenge for them as they had nowhere to dispose of sanitary towels during class time therefore some female students resorted to missing classes.

\section{CONCLUSION}

Although the shared experiences were varied within the faculty and the campus environment, the study showed that they were influenced by gender dynamics. Prominent among the experiences were affirmative action which allowed female engineering students to proceed to major in the engineering sub-discipline of their choice, initial fear of interacting with males, intimidation resulting from male dominated environment which perpetuated the stereotyping of engineering as a masculine programme. Female students were looked down upon by male students. Subtle sarcasm and differential treatment were also mentioned. Above all mathematics strongly came out as a killer course which led to some female students repeat a specific level for a year and forfeited bursary during the repeat year. Female engineering students were exposed to potential vulnerability to males due to masculinity dominance even to an extent of not having a female specific toilet in one main 
engineering building at one institution. Therefore making the environment for female engineering students friendly to females has the potential to increase participation of females in the programme.

Both Universities did not have role models in the form of lecturers in a number of sub disciplines and where they had, they were very few. Premised on this, it is recommended that the universities could consider an affirmative action in the recruitment of Student Development Fellows in their Schools of Engineering. Further, the institutions may consider providing a female friendly engineering environment. Notwithstanding the small sample size, the study illuminated many important issues facing female engineering students that cannot or have not been explored by traditional quantitative method.

\section{ACKNOWLEDGEMENT}

This article may not have been written had the female engineering students not willingly accepted to be interviewed. For this, a big thank you goes to them.

\section{REFERENCES}

[1] Blickenstaff, J. C. (2005). Women and science careers: Leaky pipeline or gender filter. 17(4), 369-386.

[2] Brainard, S., \& Linda, G. (1998). A Six-Year Longitudinal Study of Undergraduate Women in Engineering and Science. Journal of Engineering Education, 87(4), 369-375.

[3] Brocki, J. M., \& Weardon, A. J. (2006). A critical evaluation of the use of interpretative phenomenological analysis (IPA) in health psychology. Psychology and Health, 21(1), 87-108.

[4] Chongo, N. (2015). Factors influencing girls' negative mathematics self-concept at Chipembi girls' secondary school in Chisamba district of central province, Zambia. University of Zambia: Master's thesis

[5] Chou, P. N., \& Chen, W. F. (2015). Female Engineering Students' Perceptions of College Learning Experiences: A Qualitative Case Study in Taiwan. International Journal of Engineering Education, 31(1 A), 2-11.

[6] Correll, S. (2001). Gender and the career choice process: The role of biased self-assessments. 106(6), 1691-1730.

[7] Government Accountability Office. (2016). Gender Issues: Women's Participation in the Sciences. Journal of Education and Practice, 7(25).

[8] Hall, R. M., \& Sandler, B. R. (1982). The classroom climate: A chilly one for women. Washington, DC: Association of American Colleges.

[9] Hill, C., Corbett, C., \& St. Rose, A. (2010). Why So Few? Women in Science, Technology, Engineering, and Mathematics. Washington, DC: American Association of University Women.

[10] Hosaka, M. (2013). “ I Wouldn’t Ask Professors Questions!” Women Engineering Students' Learning Experiences in Japan. International Journal of Gender, Science \& Technology, 5(2).

[11] Kelly, J. (2000). Gender and Equity in Training and Teaching Behavior. 27(3).

[12] Madara, D. S., \& Cherotich, S. (2016). Challenges Faced by Female-Students in Engineering-Education. Journal of Education and Practice, 7(25). Retrieved from www.iiste.org

[13] Mahani, S., \& Molki, A. (2011). Factors influencing female Emirati students' decision to study engineering. Global Journal of Engineering Education, 13(1).

[14] McLoughlin, L. A. (2005). Spotlighting: Emergent gender bias in undergraduate engineering education. Journal of Engineering Education, 94(4).

[15] Morris, L. K., \& Daniel, L. G. (2008). Perceptions of Chilly Climate Differences in Traditional and Non Traditional Majors for Women. Research in Higher Education, 49(3), 256 - 273.

[16] Schaefer, A. (2006). A new approach to increasing diversity in engineering at the example of women in engineering. European Journal of Engineering Education, 31(6), 661-671.

[17] Seymour, E. (1995). The Loss of Women from Science, Mathematics, and Engineering Undergraduate Majors: An explanatory Account. Science Education, 79(4), 437-473.

[18] Starobin, S. S., \& Laanan, F. S. (2005). Influence of precollege experience on self-concept among community college students in science, mathematics, and engineering. Journal of Women and Minorities in Science and Engineering, 11(3), 209-230. https://doi.org/doi:10.1615/JWomenMinorScienEng.v11.i3

[19] Starovoytova, D., \& Cherotich, S. (2016). Female Underrepresentation in Undergraduate Education: Case study in School of Engineering. Research on Humanities and Social Sciences, 6(14).

[20] Wentzel, K., \& Wigfiel, A. (Eds.). (2009). Achievement goal theory: The past, present, and future. In Handbook of motivation at school (pp. 77-104). New York, NY: Routlege. 
[21] Willig, C. (2001). Introducing qualitative research in psychology: Adventures in theory and method. Berkshire, United Kingdom

\section{AUTHORS' BIOGRAPHY}

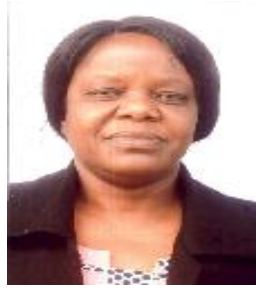

HEATHER MUNACHONGA has been working as Senior Programme Officer responsible for education programmes for the past 10 years at the Zambia National Commission for UNESCO. She received her Master's Degree in International Education and Development from Oslo Metropolitan University. She is a $\mathrm{PhD}$ candidate at the University of Zambia. Heather has contributed a Chapter to a book on HIV/AIDS and co-edited a book on Education for Sustainable Development (ESD). The edited book is a compilation of ESD Good Practices in Colleges of Education in Zambia.

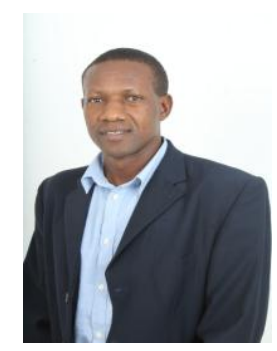

ECLOSS MUNSAKA has been teaching educational psychology at the University of Zambia for the past 16 years. He received his doctoral degree in psychology from the University of Cape Town. Apart from teaching, Ecloss is an experienced author. He has published several articles in international journals and has written three psychology text books, which are being used as core reference materials at the University of Zambia and at most colleges of education in Zambia. More than 5,000 copies of these text books have been sold throughout the country. Ecloss is a member of the International Society for the Study of Behavioural Development (ISSBD) and the Association for Psychological Sciences (APS).

Citation: Heather Munachonga, Ecloss Munsaka. "Gendered Experiences of Female Engineering Students in Selected Public Universities in Zambia". International Journal of Humanities Social Sciences and Education (IJHSSE), vol. 6, no.10, 2019, pp. 110-116. doi: http://dx.doi.org/10.20431/2349-0381.0610013.

Copyright: (C) 2019 Authors. This is an open-access article distributed under the terms of the Creative Commons Attribution License, which permits unrestricted use, distribution, and reproduction in any medium, provided the original author and source are credited. 